\title{
Genetic Instability of Sporulation-associated Characters in a Bacillus subtilis Mutant: Relationship between Sporulation, Segregation and the Synthesis of Extracellular Enzymes (Kinetic Studies)
}

\author{
By JOSEPH ZUCCA,* GEORGES BALASSA $\dagger$ \\ Unité de Microbiologie, C.N.R.S., Montpellier, France \\ J. C. F. SOUSA AND M. T. SILVAł: \\ Centre of Experimental Cytology, University of Porto, Porto, Portugal
}

(Received 1 August 1978; revised 16 October 1978)

\begin{abstract}
In the genetically unstable, protease-overproducing 'medusa' (M) strains of Bacillus subtilis, segregation of stable, wild-type-like B cells occurred mainly during sporulation. After the end of the exponential growth phase, a small fraction of $\mathrm{M}$ cells sporulated quickly and formed $\mathrm{M}$ spores, while the majority of the cells, after a 'critical period', gave rise to B segregants which sporulated after a delay. Segregation occurred without cell division. Delayed sporulation, segregation and protease overproduction are related. Similar but more complex results were obtained with the highly unstable TD strains. Sporulation and the kinetics of protease overproduction were also followed in several stable segregants. Depending on the strain, either the rate of protease production or both the rate and time course were affected. The results are interpreted in terms of sequential activation and de-activation of sporulation genes. The production of the alkaline and the neutral proteases was, in general, under common genetic control. In some strains $\alpha$-amylase was also overproduced.
\end{abstract}

\section{INTRODUCTION}

Several Bacillus subtilis mutants affected in the control of sporulation and overproducing the sporulation-associated extracellular protease have been described (Sco mutants: Milhaud et al., 1978; Dod et al., 1978). Most of them were genetically stable, but an unusual mutant exhibiting genetic instability was also found; this possessed a complex segregation pattern (Zucca \& Balassa, 1979). Preliminary observations suggested that the genetic instability was related to sporulation in that (i) segregation occurred mainly during sporulation and (ii) the characters which segregated concerned the sporulation frequency and the production of sporulation-associated enzymes. This prompted us to follow the kinetics of sporulation, segregation and the production of extracellular enzymes in the genetically unstable 'medusa' (M) strains and in some of the typical segregants.

\footnotetext{
* Present address: ENITIAA, 44072 Nantes, France.

$\dagger$ Present address: 10 Impasse Pierre Rouge, 34000 Montpellier, France.

$\ddagger$ Present address: 1021, Rua di Campo Alegre, Porto, Portugal.
} 
Table 1. Characteristics and origin of the $M$ strains and their segregants

\begin{tabular}{|c|c|c|c|c|c|c|}
\hline Type & Strain & Origin* & Segregation & Segregants & $\begin{array}{c}\text { Sporulation } \dagger \\
(\%)\end{array}$ & $\begin{array}{l}\text { Protease } \\
\text { activity: }\end{array}$ \\
\hline Wild type & $\begin{array}{l}168 \\
\text { SB5-2 }\end{array}$ & - & - & - & $\begin{array}{l}85 \\
75\end{array}$ & $\begin{array}{l}0 \cdot 14 \\
0 \cdot 19\end{array}$ \\
\hline \multirow[t]{3}{*}{$\mathbf{M}$} & FS32 & Seg. of FF15 & Fast & $\begin{array}{l}\mathbf{M} \\
\mathbf{B}\end{array}$ & $\begin{array}{r}100 \\
37\end{array}$ & $1 \cdot 25$ \\
\hline & AB35 & Tf., donor FF15 & Fast & $\begin{array}{l}\text { M } \\
\mathbf{B}\end{array}$ & $\begin{array}{r}100 \\
40\end{array}$ & $1 \cdot 10$ \\
\hline & FS319 & Seg. of FS32 & Slow & $\begin{array}{l}\text { M } \\
\text { B } \\
\text { TD }\end{array}$ & $\begin{array}{r}100 \\
15 \\
0\end{array}$ & $3 \cdot 30$ \\
\hline \multirow[t]{3}{*}{ TD } & FS223 & Seg. of FF15 & Fast & $\begin{array}{l}\text { TD } \\
\text { B } \\
\text { M }\end{array}$ & $\begin{array}{c}0 \cdot 1 \\
1 \\
100\end{array}$ & $2 \cdot 00$ \\
\hline & AB34 & Seg. of AB35 & Fast & $\begin{array}{l}\text { TD } \\
\text { B }\end{array}$ & $\begin{array}{l}10 \\
30\end{array}$ & $2 \cdot 67$ \\
\hline & FS381 & Seg. of FF223 & Slow & $\begin{array}{l}\text { TD } \\
\text { B }\end{array}$ & $\begin{array}{l}0.01 \\
0.05\end{array}$ & $6 \cdot 60$ \\
\hline B & $\begin{array}{l}\text { FS156 } \\
\text { FS388 } \\
\text { FS430 } \\
\text { FS439 }\end{array}$ & $\begin{array}{l}\text { Seg. of FF15 } \\
\text { Seg. of M transformant } \\
\text { Seg. of } M \text { transformant } \\
\text { Seg. of AB35 }\end{array}$ & $\begin{array}{l}- \\
- \\
-\end{array}$ & $\begin{array}{l}- \\
- \\
-\end{array}$ & $\begin{array}{r}100 \\
33 \\
75 \\
75\end{array}$ & $\begin{array}{l}0 \cdot 28 \\
0 \cdot 10 \\
0 \cdot 25 \\
0 \cdot 25\end{array}$ \\
\hline $\mathrm{B}(\mathrm{D})$ & $\begin{array}{l}\text { FS436 } \\
\text { FS437 }\end{array}$ & $\begin{array}{l}\text { Seg. of FS32 (M) } \\
\text { Seg. of FS223 (TD) }\end{array}$ & - & - & $\begin{array}{l}100 \\
100\end{array}$ & $\begin{array}{l}1 \cdot 25 \\
0 \cdot 45\end{array}$ \\
\hline TDst & $\begin{array}{l}\text { FS336 } \\
\text { FS382 } \\
\text { AB91-2-2 } \\
\text { AB93-8-1 }\end{array}$ & $\begin{array}{l}\text { Seg. of FS223 } \\
\text { Seg. of FS } 223 \\
\text { Seg. of TD transformant } \\
\text { Seg. of TD transformant }\end{array}$ & $\begin{array}{l}- \\
= \\
-\end{array}$ & $\begin{array}{l}- \\
- \\
-\end{array}$ & $\begin{array}{l}1 \\
0 \\
0 \cdot 1 \\
0 \cdot 01\end{array}$ & $\begin{array}{r}3 \cdot 40 \\
6 \cdot 60 \\
5 \cdot 25 \\
11 \cdot 20\end{array}$ \\
\hline
\end{tabular}

* Seg., segregation; Tf., transformation.

$\uparrow$ Frequency of heat-resistant spores among the viable cells at $t_{24}$; in segregating strains each cell type is considered separately.

$\ddagger$ Protease activity in the supernatants at the end of sporulation $\left(t_{20}\right.$ to $\left.t_{24}\right)$.

\section{METHODS}

Strains. The strains used in this study and their characteristics are listed in Table 1 . They were all derived from the Marburg strain of $B$. subtilis. The two 'wild-type' control strains, 168 (trpC2) and SB5-2 (trpC2 pyr A1), were from the laboratory collection. The origin of the other strains is described in the preceding paper (Zucca \& Balassa, 1979).

Growth and sporulation. The media used and the culture conditions were as described previously (Balassa, 1969; Dod et al., 1978). Sporulating cultures were obtained by growing precultures overnight in $3 \times \mathrm{D}$ medium and inoculating $2.5 \mathrm{ml}$ preculture into $250 \mathrm{ml}$ nutrient broth in Fernbach flasks. Time $t_{0}$ was defined as the end of exponential growth; $t_{1}, t_{2}$ etc. indicate sporulation times in hours after $t_{0}$. Segregation was followed by plating samples on nutrient agar as described by Zucca \& Balassa (1979).

Enzyme assays. Total extracellular protease, seryl protease and $\alpha$-amylase in the supernatants were assayed by the methods of Dod et al. (1978).

Electron microscopy. This was done as described by Sousa et al. (1978).

\section{RESULTS}

\section{Medusa strains}

The original genetically unstable strain, FF15, forms medusa-like (M) colonies, overproduces extracellular protease activity on elastin agar and segregates. Strain FS32, the standard medusa strain, behaves in the same way as FF15, and its sporulation and segrega- 

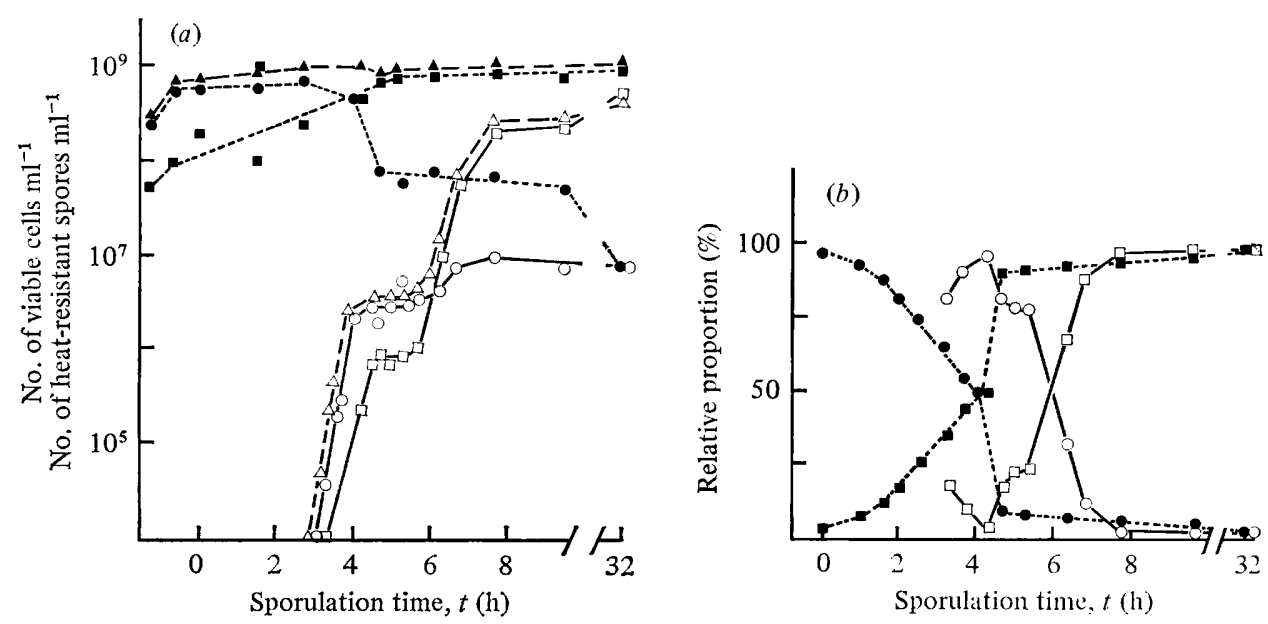

Fig. 1. Sporulation and segregation of the medusa strain FS32. (a) The numbers of viable cells and of heat-resistant spores were counted in samples taken from sporulating cultures: total viable cells $(\mathbf{A})$, total spores $(\triangle)$, viable $\mathbf{M}$ cells $(\Theta), \mathbf{M}$ spores $(\bigcirc)$, viable B cells $(\boldsymbol{\square})$ and $\mathbf{B}$ spores $(\square)$.

(b) Relative proportions of $\mathrm{M}$ and $\mathrm{B}$ cells and spores: symbols as in $(a)$.

tion were studied in detail. Unless otherwise stated, all the strains described in this study grew at the same rate as the wild type. After $t_{0}$, the absorbance of the cultures remained constant and, unless otherwise indicated, there was no sign of significant cell lysis or division (this was confirmed by electron microscopy). However, the relative proportions of $\mathbf{M}$ cells and $\mathrm{B}$ segregants did change: between $t_{0}$ and $t_{5}$ the number of $\mathrm{M}$ cells decreased while $\mathrm{B}$ cells accumulated (Fig. 1). (The exact proportion of $\mathrm{B}$ cells in the culture before $t_{0}$ and the number of $M$ cells at the end of the sporulation varied between experiments. Rare $T, W$ and TD segregants were not routinely followed in these experiments.)

Sporulation of strain FS32 was biphasic with a plateau between $t_{4}$ and $t_{6}$. A small fraction of the cells $(<1 \%)$ sporulated early; this portion of the curve resembles that for wild-type cultures. The majority of the cells, however, sporulated after a delay of about $2 \mathrm{~h}$. Since it is possible to recognize $\mathrm{M}$ and $\mathrm{B}$ colonies after plating the spores, the sporulation of the two cell types could be followed separately. Early sporulating cells were almost exclusively of the $M$ type. When sporulation of only the $M$ type cells was considered, a wild-type-like curve was obtained, most of the cells having formed heat-resistant spores by $t_{4}$ to $t_{5}$. In contrast, only a few B cells sporulated before $t_{6}$. After $t_{6}$, a large fraction of B cells sporulated, with kinetics similar to the wild type but delayed by $2 \mathrm{~h}$. The overall sporulation curve is thus the combination of two curves, namely, early sporulation of $\mathbf{M}$ cells and late sporulation of $\mathbf{B}$ cells.

Considering these observations together with the constant number of viable cells after $t_{0}$, the changes in cultures of FS32 can be summarized as follows. Before $t_{0}, \mathrm{M}$ cells dominated; they gave rise to few or no B cells during exponential growth. After $t_{0}$, a small fraction of the $M$ cells underwent normal sporulation without segregation. The majority of the cells, however, entered a 'critical period' during which they changed from the $M$ to the $B$ type. Once this change had occurred, sporulation of the B cells started and proceeded normally. The process was best followed by measuring the proportions of $\mathrm{M}$ and $\mathrm{B}$ type cells in sporulating cultures (Fig. 1b). The results suggest that for most cells the 'critical period' was between $t_{2}$ and $t_{4}$ and lasted about $2 \mathrm{~h}$. Similar changes in the proportions of $\mathrm{M}$ and $\mathrm{B}$ spores occurred about $2 \mathrm{~h}$ later, suggesting that the change from $\mathrm{M}$ to $\mathrm{B}$ type took place in cells $2 \mathrm{~h}$ before they formed mature spores, i.e. around stage III. The most likely interpretation of the results is that sporulating $M$ cells, at around stage III, may develop in one of two ways: either they sporulate fast or they enter a 'critical period' and, most frequently, change to B 


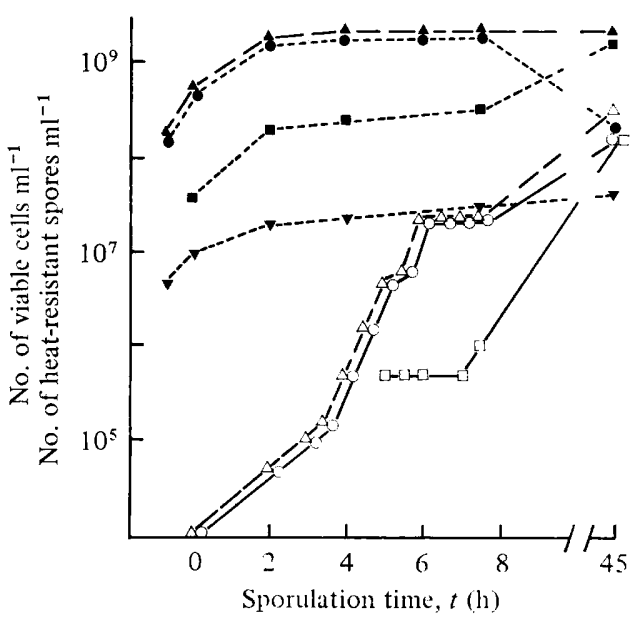

Fig. 2

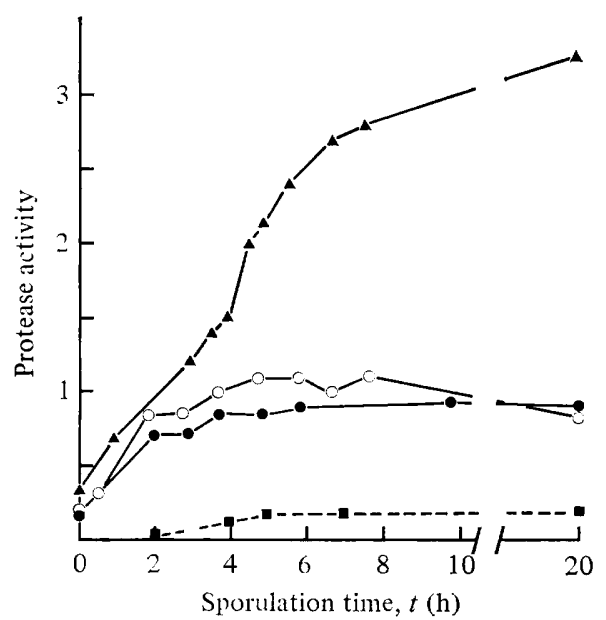

Fig. 3

Fig. 2. Sporulation and segregation of the medusa strain FS319. Legend as in Fig. 1(a); viable TD cells $(\boldsymbol{\nabla})$ were also counted.

Fig. 3. Protease production by medusa strains. Protease activity was measured in the supernatants of the medusa strains FS32 (O), AB35 (O) and FS319 ( $\boldsymbol{\Delta})$ and of the wild-type strain SB5-2 ( $\boldsymbol{D})$.

cells which, in turn, sporulate after a delay. Sporulation of the newly formed B cells might be incomplete, with only 15 to $40 \%$ forming spores. In contrast, it seems that all $\mathrm{M}$ cells sporulate, either fast or after a delay.

Several other $\mathrm{M}$ clones, including those obtained by transformation of wild-type strains with FF15 or FS32 as donor (i.e. AB35, AB72, see Zucca \& Balassa, 1979), exhibited exactly the same behaviour as FS32 (results not shown). Another type of M clone found (FS319) formed $M$ colonies, segregated B cells and, in addition, up to $5 \%$ TD cells. However, in this strain segregation occurred much more slowly: at $t_{8}$ most of the cells were still of the $M$ type and B cells accumulated much later (Fig. 2). The number of TD cells also slowly increased. Both $\mathrm{M}$ and $\mathrm{B}$ cell types sporulated after a delay. The number of $\mathbf{M}$ spores increased slowly until $t_{5}$ and then reached a plateau; B spores apparently developed only after $t_{7}$, with the exception of a small number of earlier spores. (Because of the unexpectedly late sporulation of this strain, no detailed sporulation kinetics were obtained. However, comparison of the number of $\mathrm{M}$ and $\mathrm{B}$ spores at $t_{7}$ and at $t_{45}$ strongly suggested that sporulation was biphasic). Thus, strain FS319 behaved in much the same way as strain FS32, but had a longer 'critical period'.

Protease accumulation was followed in the supernatants of sporulating medusa cultures. Most medusa strains had protease activities about five times that of the wild-type SB5-2 (Table 1). For strains FS32 and AB35, the kinetics of protease production were similar to those for the wild type and for $S c o C$ strains (Dod et al., 1978), with fast production for about $3 \mathrm{~h}$ followed by a plateau or slow accumulation (Fig. 3). The period of fast protease production occurred early: it started before $t_{0}$ and stopped between $t_{2}$ and $t_{3}$. In contrast, FS319, the slowly segregating strain, produced protease at the same high rate for at least $8 \mathrm{~h}$ and accumulated about 20 times the normal amounts.

\section{Segregating TD strains}

Segregating TD strains were highly unstable. They segregated M, B and, more rarely, stable TD clones and sporulated at low frequencies (Zucca \& Balassa, 1979). A typical strain is FS223 (Fig. 4). At $t_{0}$, FS223 cultures were heterogeneous, containing TD, B and M cells. This heterogeneity originated, at least partially, from the inoculum: TD colonies and 

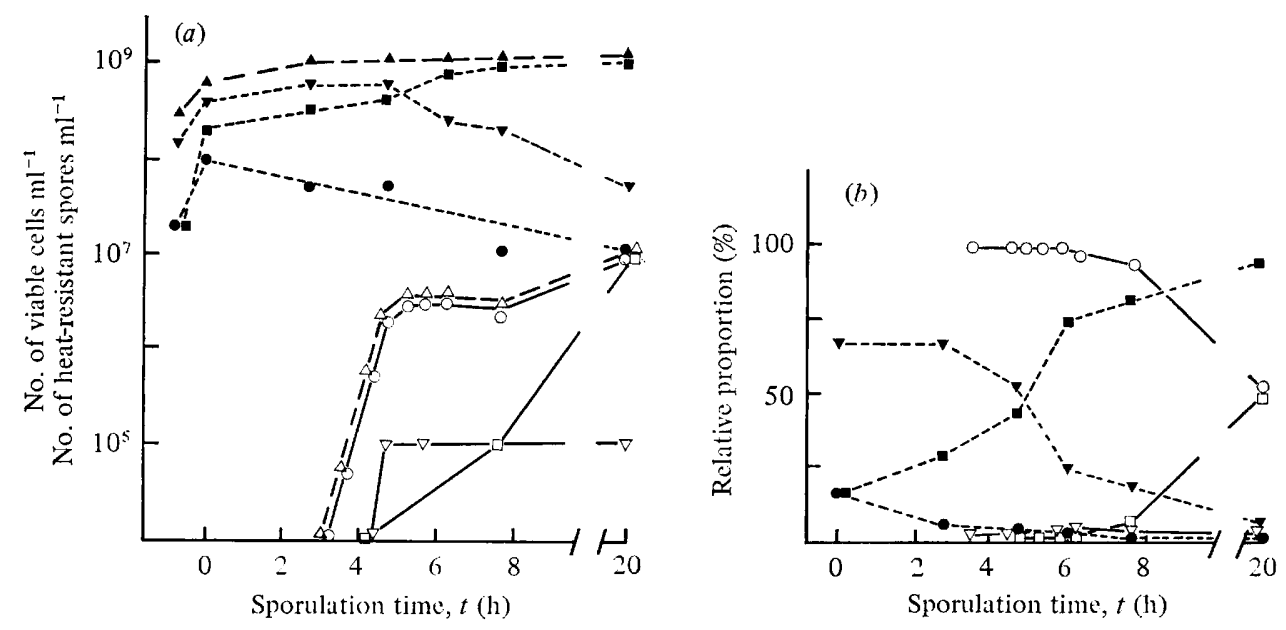

Fig. 4. Sporulation and segregation of the TD strain FS223. Legend as in Fig. 1; viable TD cells $(\nabla)$ and TD spores $(\nabla)$ were also counted.

agar slabs always contained $\mathbf{M}$ and $\mathbf{B}$ cells. It is not known if segregation also occurred during exponential growth. After $t_{0}$ the number of TD cells slowly decreased; this was partly due to lysis. The number of $M$ cells also decreased while $B$ cells accumulated, in the same way as in medusa cultures. The number of $\mathrm{M}$ cells was, however, always too low to provide all the B cells. Thus, the latter derive to a large extent from TD cells, either directly or by a two-step process through $\mathbf{M}$.

Only a small fraction of the cells sporulated early, and these were mainly of the $M$ type. The sporulation frequency of TD cells was very low $\left(10^{-3}\right.$ to $\left.10^{-4}\right)$, the rare TD spores being formed early. B cells sporulated very late and at low frequency. This was true only for the newly formed B cells: B clones isolated after plating unheated TD cultures sporulated at high frequency (see below). The results are difficult to interpret because of the more complex segregation pattern and the possibility that B cells arise either from TD cells or from $M$ segregants.

It seems that TD cells in sporulating cultures undergo one of four possible patterns of development: (i) no segregation and sporulation at very low frequency; (ii) change to $M$ type and rapid sporulation; (iii) a long 'critical period' followed, directly or via $\mathrm{M}$, by a change to B type and late sporulation; and (iv) as (iii) but without sporulation. Judging from the long delay in sporulation and the length of time between the increase in frequency of viable B cells and that of B spores (Fig. $4 b$ ), the 'critical period' for TD cells lasts several hours.

Strain AB34, a TD strain derived from AB35, behaved in a similar way to FS223 except that it segregated somewhat faster (Fig. 5). Few M segregants were found, the major pattern of segregation being from TD to $\mathrm{B}$. (This would argue against $\mathrm{M}$ being an obligatory intermediate between TD and B.) TD cells sporulated at a higher frequency $\left(10^{-1}\right)$ with wildtype-like kinetics. B cells sporulated at normal frequency (30\%) but with a marked delay. Judging from the changes of the proportions of TD and B types among viable cells and spores (Fig. $5 b$ ), the critical period lasts about $3 \mathrm{~h}$.

Various segregating TD clones appeared to differ in their rate and time of segregation, their frequency of sporulation and the length of their 'critical period'. For instance, FS381, derived from FS223, segregated very slowly and even the B segregants sporulated only at low frequency (results not shown).

Protease was extensively overproduced by TD strains, to 10 to 30 times the wild-type activity (Fig. 6). This was due both to a high rate and to a long period of production, 

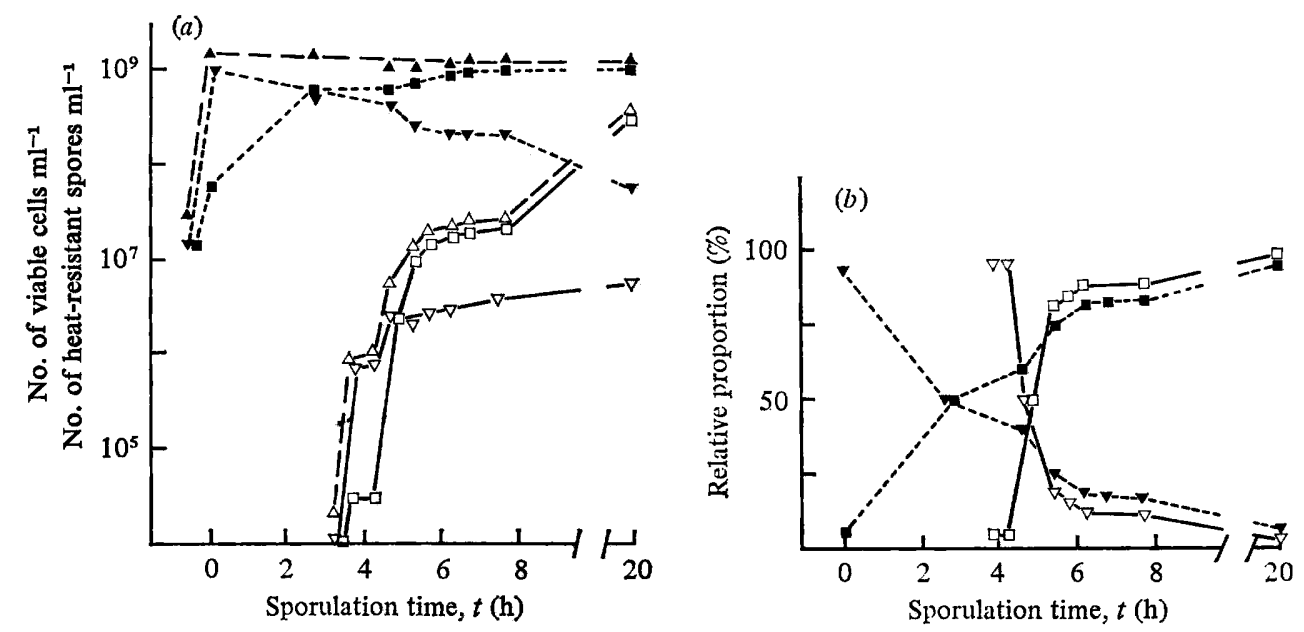

Fig. 5. Sporulation and segregation of the TD strain AB34. Legend as in Fig. 4.

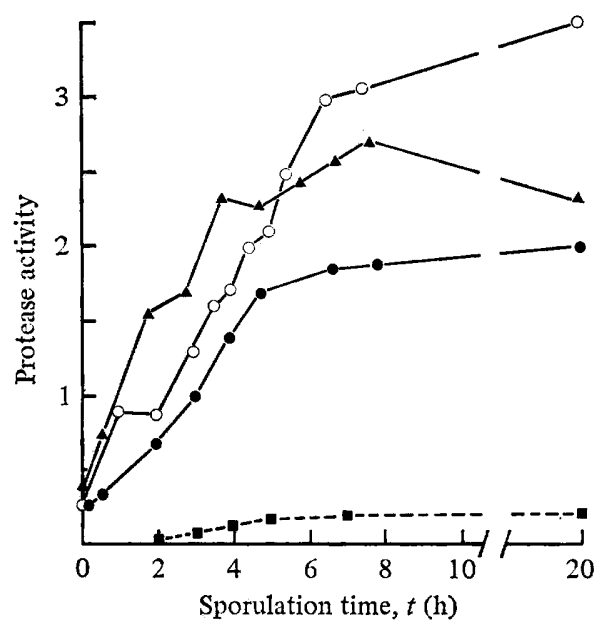

Fig. 6. Protease production by TD strains. Protease activity was measured in the supernatants of the TD strains FS223 (O), FS381 (O) and AB34 (A) and of the wild-type strain SB5-2 ( $\boldsymbol{\square}$ ).

starting before $t_{0}$ and continuing until $t_{5}$ to $t_{8}$. The strain which segregated most slowly and in which sporulation was most delayed (FS381) produced the most protease.

\section{Stable B segregants}

$M$ and TD strains both segregated B clones at high frequency. The latter were genetically stable, formed brown colonies, generally showed normal elastolytic activity and appeared, in all respects, to be similar to wild-type strains. Strain FS156, a typical B strain, sporulated at high frequency following a normal time course and produced normal amounts of protease (Fig. 7). The same was true for most of the B strains (i.e. FS388, FS430, FS439, AB53 and AB73, results not shown; see Table 1, and Zucca \& Balassa, 1979) derived by segregation either from FS32 or from M or TD transformants.

B(D) strains - stable strains forming brown colonies but showing high elastolytic activity $\left(E l^{D}\right)$ - were obtained less frequently. Two of them, one derived from an $M$ strain and the other from a TD strain, were studied in detail. Strain FS436 (Fig. 7) sporulated normally but produced six times more protease than the wild type. Protease production took place at a 

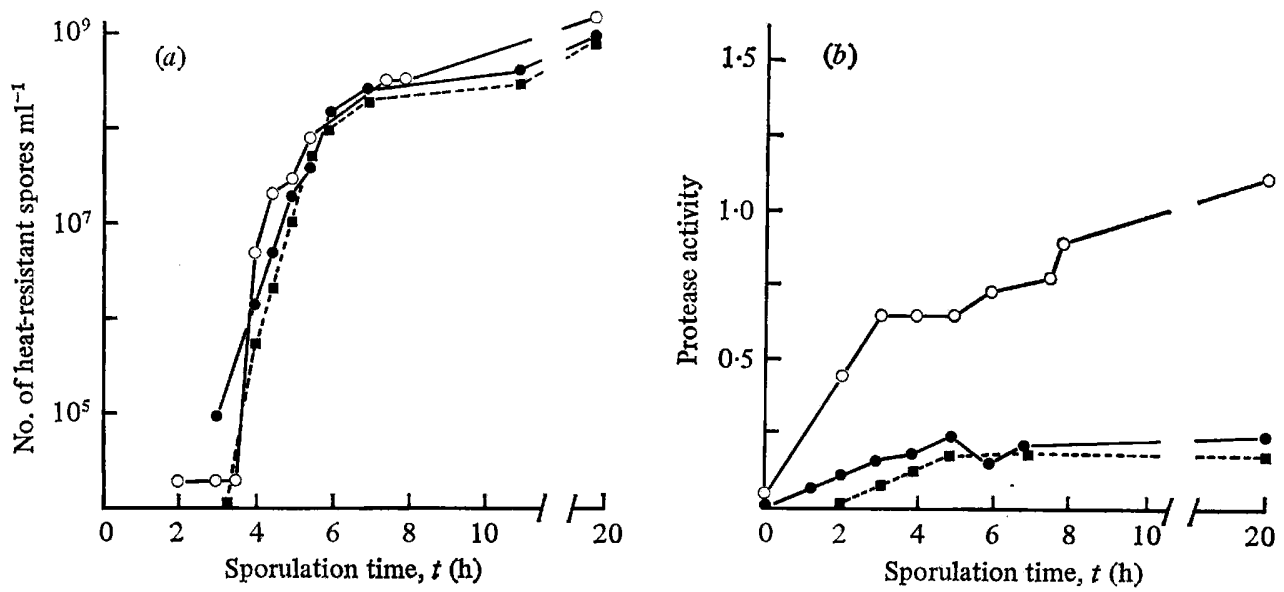

Fig. 7. Sporulation and protease production in stable B and B(D) segregants. The development of heat-resistant spores $(a)$ and the production of extracellular protease $(b)$ were followed during sporulation of the stable B segregant FS156 (O), the stable B(D) segregant FS436 (O) and the wild-type strain SB5-2 ( $\square$ ).
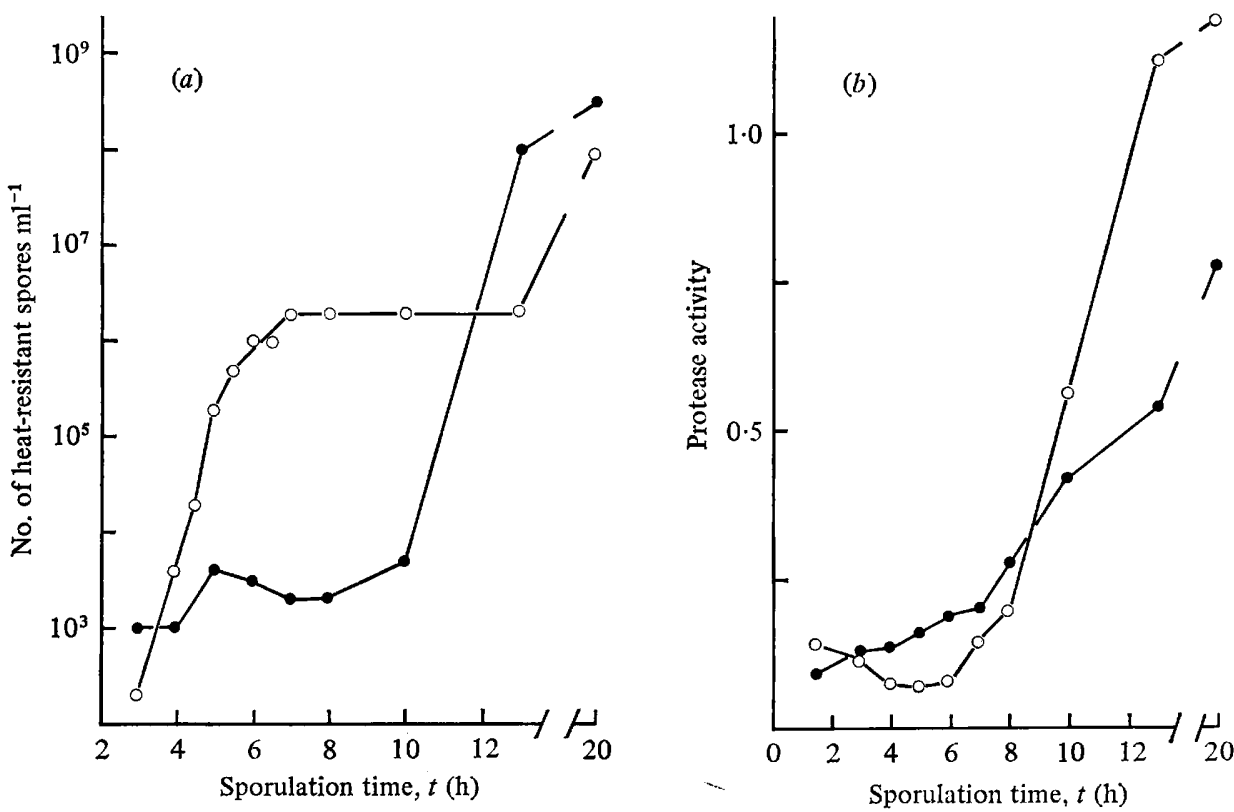

Fig. 8. Sporulation and protease production in $B(D)$ strains. The development of heat-resistant spores $(a)$ and the production of extracellular protease $(b)$ were followed during sporulation in the stable B(D) segregant FS437 (O) and in the B(D) transductant AD19 (O).

high rate from $t_{0}$ to $t_{3}$ and then continued at a low rate. This strain resembled the $S c o C$ mutants. Strain FS437, on the other hand, did not sporulate until $t_{10}$ to $t_{12}$ (Fig. 8). Protease production was also delayed: the maximum rate was not reached until $t_{6}$ and a large proportion of the enzyme was produced after $t_{12}$. This strain resembled the $S c o D$ mutants in its behaviour.

Stable $\mathrm{El}^{\mathrm{D}}$ clones were also obtained by transduction with $\mathrm{M}$ donors (Zucca \& Balassa, 1979). Two such clones carrying a $S c o$ mutation linked to $\arg C$ (presumably $S c o C$ ) have been examined. They both sporulated very late, with peculiar, probably biphasic kinetics 

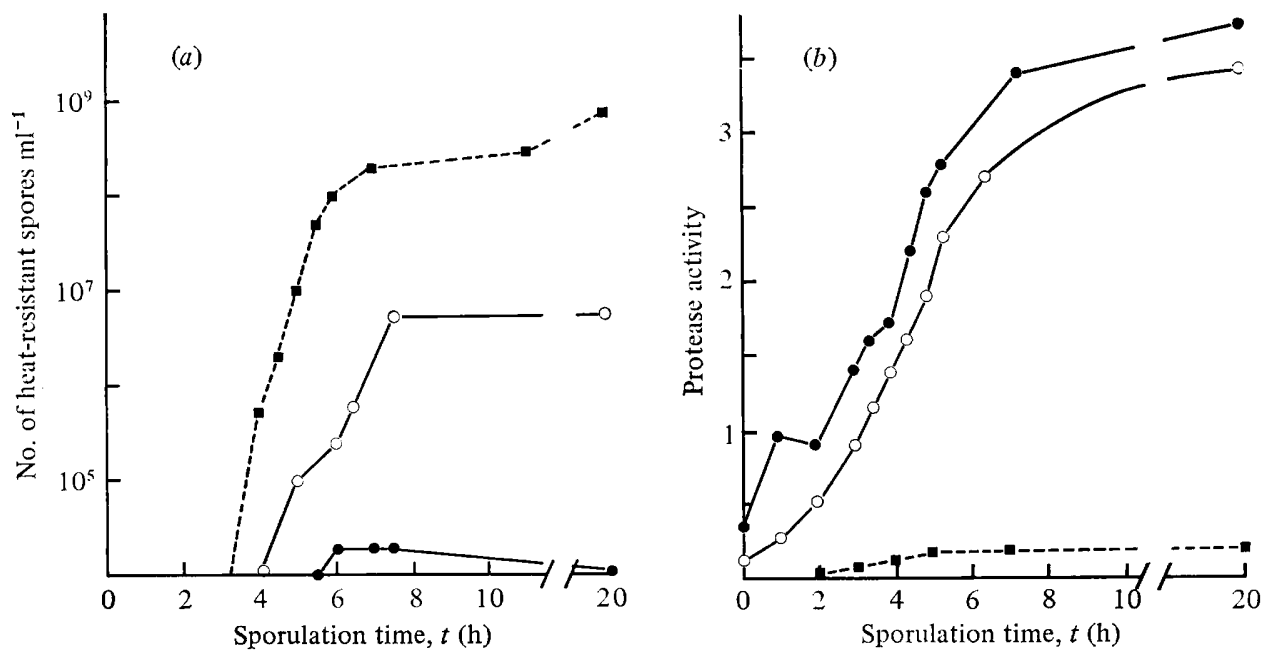

Fig. 9. Sporulation and protease production in TDst segregants. The development of heat-resistant spores $(a)$ and the production of extracellular protease $(b)$ were followed during sporulation of the stable TDst segregants FS336 $(O)$ and FS382 (O) and the wild-type strain SB5-2 ( $\square)$.
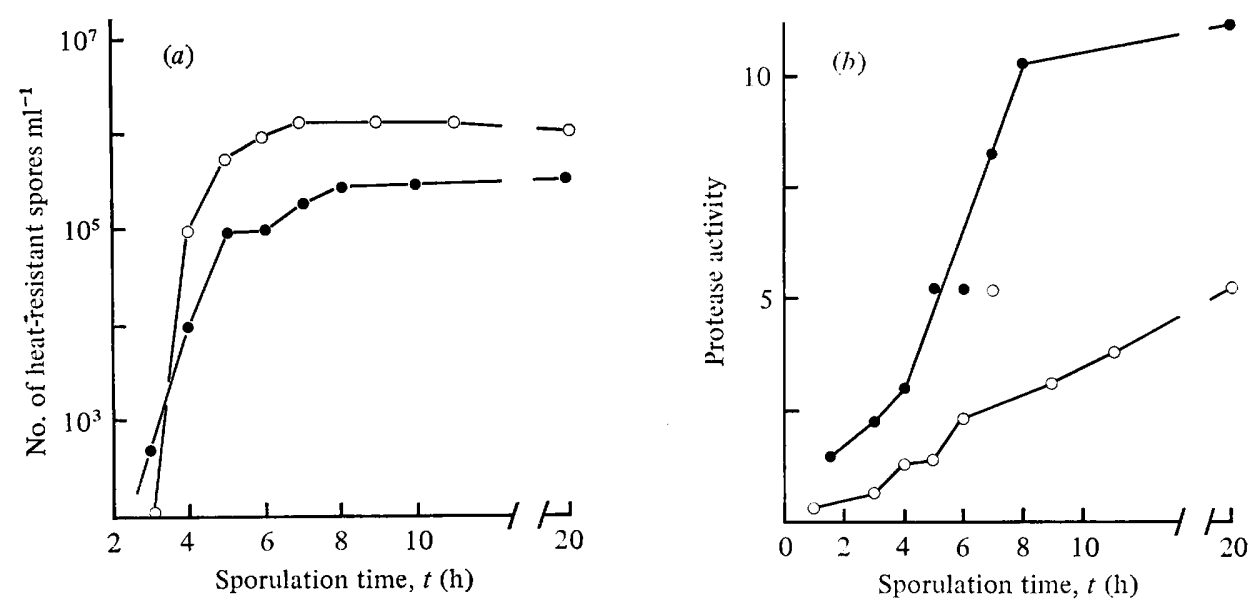

Fig. 10. Sporulation and protease production in TDst transformants. The development of heatresistant spores $(a)$ and the production of extracellular protease $(b)$ were followed during sporulation of two TDst strains derived from TD transformants, AB91-2-2 (O) and AB93-8-1 (O).

(results for AD19 are shown in Fig. 8). Protease synthesis was also very late $\left(t_{8}\right.$ to $\left.t_{12}\right)$. These results are, however, difficult to interpret since the transductants, in contrast to all the other strains described in this study, had an abnormal growth pattern: early exponential growth was followed by extensive lysis and secondary growth. Moreover, the sporulating cultures contained a large number of phage particles (G. Balassa, J. C. F. Sousa \& M. T. Silva, unpublished).

\section{TDst strains}

Occasionally, TD strains gave rise to stable strains, forming transparent colonies, sporulating at low frequency and producing high levels of protease. Four such TDst strains have been examined, two derived from FS32 and two obtained by segregation of TD transformants. They all sporulated at low frequency $\left(10^{-3}\right.$ to $\left.10^{-5}\right)$ with normal or somewhat delayed kinetics (Figs 9, 10). They produced 20 to 60 times more protease than normal. 
Table 2. Proportions of seryl-protease and metallo-protease in supernatants

The contribution of the seryl-protease was measured as the percentage of the total activity that was inhibited by PMSF. The metallo-protease, which is not inhibited by PMSF, was responsible for the remaining activity.

\begin{tabular}{llccc}
\multicolumn{1}{c}{ Type } & $\overbrace{t_{2}-t_{3}}$ & $t_{7}-t_{9}$ & $t_{19}-t_{24}$ \\
168 & Wild type & 64 & 77 & 78 \\
SB5-2 & Wild type & - & - & 80 \\
FS32 & M & 57 & 67 & 74 \\
FS319 & M & 58 & 59 & - \\
AB35 & M & 53 & 63 & - \\
FS223 & TD & 61 & 65 & 80 \\
AB34 & TD & 66 & 64 & - \\
FS156 & B & - & - & 86 \\
FS436 & B(D) & 67 & 73 & - \\
FS437 & B(D) & 25 & 46 & 73 \\
FS336 & TDst & 60 & 63 & - \\
AB91-2-2 & TDst & - & 66 & 83 \\
& &
\end{tabular}

(The quantities of protease might be even higher since our assay system was not calibrated for such high activities.) Protease production started at (or just before) $t_{0}$ at a high rate and continued at the same rate for at least $8 \mathrm{~h}$.

\section{Overproduction of the two proteases}

Bacillus subtilis produces two extracellular proteases during sporulation - an alkaline seryl-protease, strictly associated with sporulation, and a neutral metallo-protease, more or less independent of sporulation (Millet, 1970; Doi, 1972; Dod et al., 1978). The two enzymes can be distinguished by using specific inhibitors, such as phenylmethylsulphonyl fluoride (PMSF) which inhibits the seryl-protease but not the metallo-enzyme. Stable Sco mutants overproduce both enzymes in approximately the same proportions (Dod et al., 1978). The relative proportions of the two enzymes were measured in the supernatants of various strains; typical results are shown in Table 2. The proportions of the two enzymes were similar in nearly all of the strains, the seryl-protease being responsible for about $60 \%$ of the total proteolytic activity in early samples and up to $80 \%$ in late samples. Since total proteolytic activity varied from one strain to another by a factor of up to 60 without any significant change in the proportion of the two enzymes, it seems that the quantitative regulation of the seryl- and metallo-proteases is coordinate, as it is in the various Sco mutants (Dod et al., 1978; Dod \& Balassa, 1978).

Strain FS437 was exceptional. Early samples contained $75 \%$ metallo-protease, although the proportions of the two enzymes were normal in late samples. Since sporulation of this strain is much delayed, it seems that after $t_{0}$ the majority of the cells, not yet involved in sporulation, produced only the metallo-enzyme and the seryl-protease did not accumulate until later when sporulation had started. Similar results were observed with $S c o D$ strains (Dod et al., 1978).

\section{Production of $\alpha$-amylase}

$\alpha$-Amylase is an extracellular enzyme which is produced by $B$. subtilis in the stationary phase but is independent of sporulation (Schaeffer, 1969; Balassa, 1969). It is produced normally by stable $S c o C$ strains (Dod et al., 1978). Medusa strains produced either normal or slightly elevated amounts of the enzyme (Table 3). Overproduction, if any, was never more than three- to fourfold, whereas protease was overproduced 5- to 16-fold. As expected, 
Table 3. Production of $\alpha$-amylase

Enzyme activity was measured in the supernatants of cultures at $t_{20}$ to $t_{24}$.

Strain

Various $\mathrm{Sco}^{+}$strains

Various Sco mutants

Four M strains

Six B segregants

FS223 [TD]

FS437 [B(D)]

AB91-2-2 [TDst]

AB93-8-1 [TDst]
$\alpha$-Amylase activity

19-50*

20-79*

23-124

$35-52$

69

169

355

481

* From Dod et al. (1978).

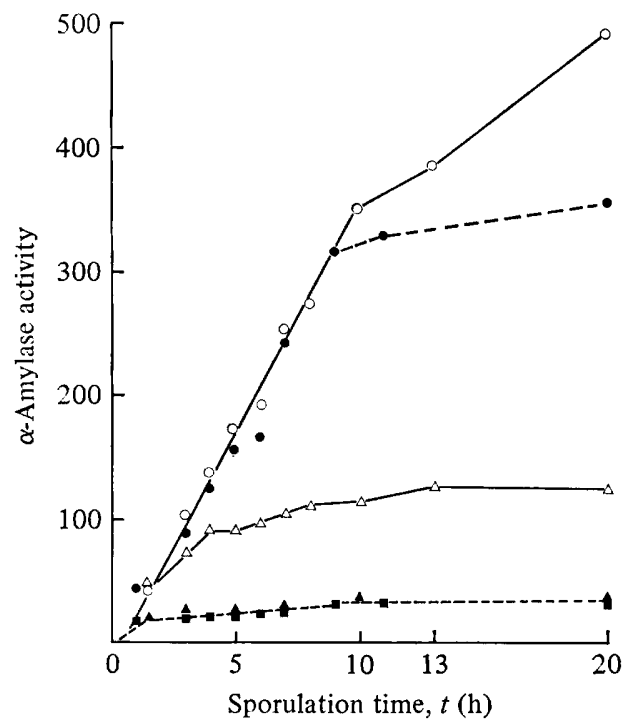

Fig. 11. Production of $\alpha$-amylase. $\alpha$-Amylase activity was measured in the supernatants of the wild-type strain PM37 $(\square)$, the medusa strains AB53 $(\Delta)$ and AB72 $(\triangle)$ and the TDst "strains AB91-2-2 (O) and AB93-8-1 (O).

B segregants produced normal amounts of $\alpha$-amylase. However, strain FS437 was again exceptional in that it produced about five times the normal amount of the enzyme. Even higher activities were found with the TDst strains. It appears that the syntheses of $\alpha$-amylase and protease are independent in most strains including $M$ strains. However, in at least one B(D) strain and in TDst strains, overproduction of $\alpha$-amylase and the extracellular proteases was concomitant.

In wild-type and $S c o A$ strains, $\alpha$-amylase was produced at a constant rate from $t_{0}$ to $t_{3}$, and then at a slower rate until $t_{12}$. The kinetics were similar for the M strain AB72. In contrast, the TDst strains (Fig. 11) and FS437 (not shown) produced the enzyme at a constant high rate until $t_{10}$, the kinetics resembling that for protease production (Fig. 10).

\section{Electron microscopy}

$M$ cells appeared normal, and no difference was found between $M, B$ and wild-type cells. A typical cell containing a mature spore is shown Fig. 12. (Since most M cells change to B during sporulation, it is not possible to observe by electron microscopy the rare cells which yield $\mathrm{M}$ spores. TD strains were not examined because of their high genetic instability.) 


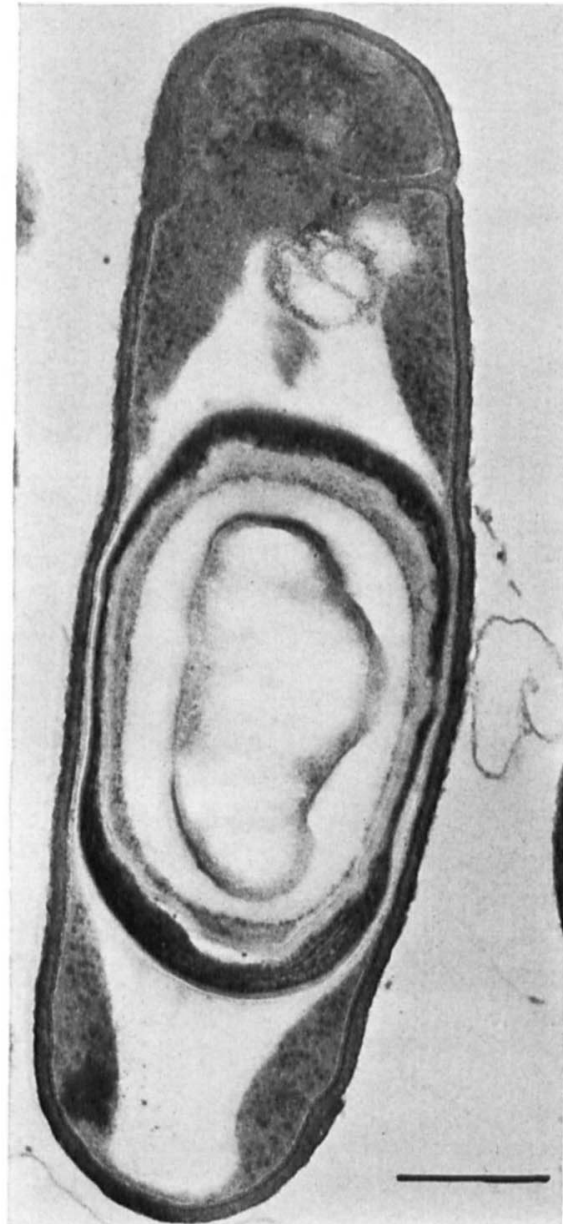

Fig. 12

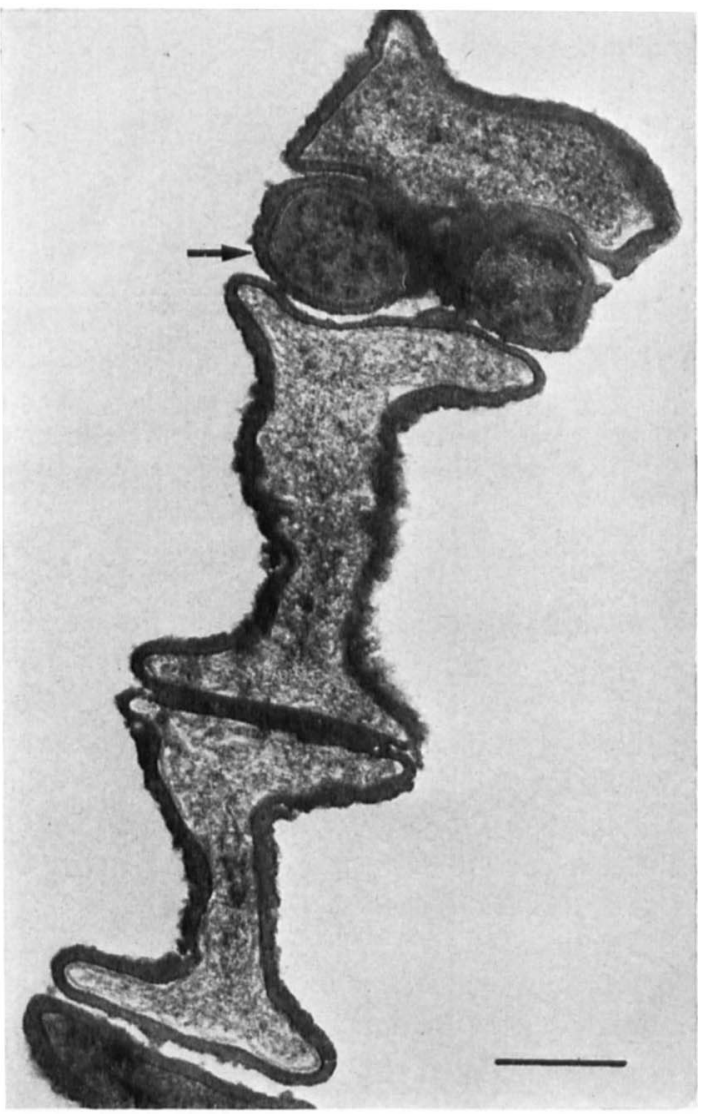

Fig. 13

Fig. 12. A typical $M$ spore. Thin section of a cell from an overnight culture of $A B 35$, containing a mature spore. The spore is normal; the inner coat has 4 to 5 layers. Bar marker represents $0.5 \mu \mathrm{m}$.

Fig. 13. Abnormal TDst cells. Thin section of cells from an overnight culture of AB34-1, a TDst strain. Note the irregular thickness of the cell wall. Most cells of the chain show signs of lysis. Small spherical cells (arrow) are also present. Bar marker represents $0.5 \mu \mathrm{m}$.

TDst strains are asporogenous, have a peculiar colony morphology and are also cytologically abnormal. Growing cells appeared to be like wild-type cells. Most cells sampled after $t_{0}$ (between $t_{3}$ and $t_{20}$ ) showed no sign of sporulation and remain at stage 0 . Moreover, they frequently showed signs of autolysis and gross deformation of the cell wall. Many assumed a star-like or bone-shaped form (Fig. 13).

The delayed and biphasic sporulation of M strains prompted us to follow their morphogenesis in detail, as already done with the stable Sco mutants (Sousa et al., 1978). Figure 14 shows typical results obtained with an $M$ transformant. As with the wild type, stages II and IV are short. Stage III is somewhat delayed, but the most important difference from the wild type is the delay and prolongation of stage $V$ : the majority of the cells remained at this stage from $t_{6}$ to $t_{10}$. This was not the case with the $\mathrm{B}$ segregants. 


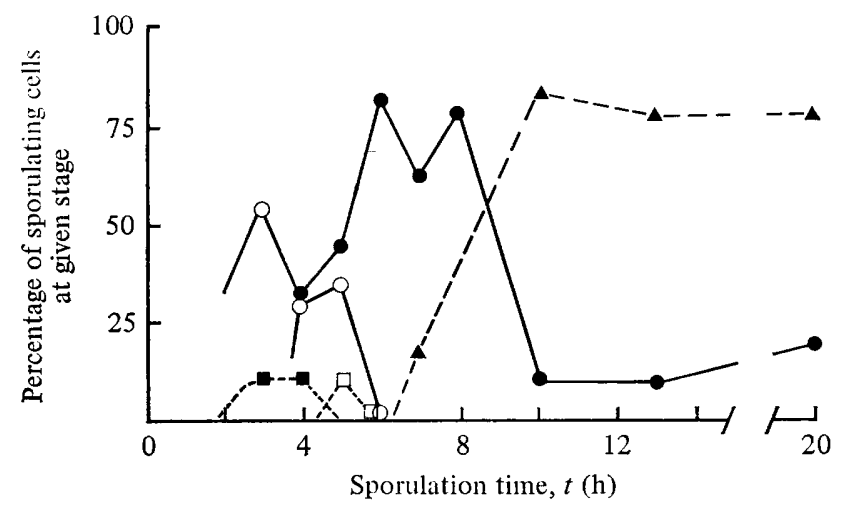

Fig. 14. Morphogenesis of the medusa strain AB35. Samples taken from a sporulating culture were examined by electron microscopy. The numbers of cells at stages II ( $\square)$, III (O), IV ( $\square$ ), $\mathrm{V}(\boldsymbol{O})$ and VI $(\boldsymbol{\Delta})$ are expressed as percentages of the total number of sporulating cells.

\section{DISCUSSION}

Relationship between segregation and sporulation. Our experiments show that the irreversible genetic event which transforms $\mathrm{M}$ cells into B cells occurs essentially during sporulation, in the absence of cell division. Segregation from $M$ to $B$ during exponential growth occurs either rarely or never. It is possible that the few $\mathrm{B}$ cells present at $t_{0}$ in $\mathrm{M}$ cultures arose during growth, but they might also have originated from $B$ cells present in the inoculum. The relationship between segregation and spore formation was further confirmed in that $M$ cultures grown in conditions where sporulation is poor (synthetic media with glucose) segregated less B cells (unpublished).

$\mathrm{B}$ cells arise after $t_{0}$ - mainly between $t_{2}$ and $t_{4}$. The appearance of B cells preceded the appearance of $B$ spores by about $2 \mathrm{~h}$. A kinetic analysis of sporulation and segregation of $M$ cultures led to the conclusion that a small fraction of $\mathrm{M}$ cells sporulate with a normal time course yielding $\mathrm{M}$ spores, while the majority of the cells stop sporulating during a 'critical period' of about $2 \mathrm{~h}$. During this time, most $M$ cells change into B cells and the latter resume sporulation. Heterogeneity of the populations and asynchrony of sporulation prevent precise identification of the 'critical period' with a sporulation stage but it is likely that many of the cells reach stage III before or during the 'critical period'. Cytological studies confirmed the delay of sporulation: accumulation of cells at stages III and V was particularly marked. Cells at stage III might be in the 'critical period' while stage V cells appear after segregation and are, therefore, of the B type. The kinetics of morphogenesis of $M$ strains resemble those of stable $S \operatorname{co} A, B$ and $D$ mutants (Sousa et al., 1978).

Occasionally $M$ strains were found which showed a much longer delay in sporulation and slower segregation with a longer 'critical period'. This confirms the correlation between segregation and sporulation and suggests that not all the $M$ clones are genetically identical.

Delayed sporulation of B segregants is due directly to the genetic event of segregation: once isolated, clones of B segregants sporulated normally, by monophasic kinetics, without any delay.

Segregation of $\mathrm{M}$ and $\mathrm{B}$ cells in TD cultures is more complex than that of $\mathrm{M}$ strains, but occurs in a similar way. At least the majority of both $M$ and $B$ segregants arise from TD cells during sporulation (i.e. after $t_{0}$, in stationary cultures where wild-type cells would sporulate). B segregants derive either directly from TD cells or indirectly from $\mathrm{M}$ segregants. In the latter case, the intermediate $M$ stage should be short. Since TD cells sporulate only at low frequency, for them the 'critical period' has a different meaning: the majority of the cells have the 'choice' between segregation (to $M$ or B) and maintenance without sporulation. 
Since the genetic composition of $\mathrm{M}$ cells is not clearly established, only tentative suggestions about the nature of the segregation event can be made. We have suggested (Zucca \& Balassa, 1979) the presence of a tandem duplication, of a segregation factor or of some other genetic anomaly. B cells could arise by loss of the duplication due to intra- or inter-chromosomal recombination or by some other mechanism. The reason why this occurs only (or preferentially) during the 'critical period' in sporulating cultures is not known. Quantitative or qualitative changes of the enzymes involved in recombination or biochemical events related to DNA replication might be involved (Aubert et al., 1968, 1969; Ryter \& Aubert, 1969). Thus, although segregation is not accompanied by cell division, it might be concomitant with chromosome replication.

Overproduction of extracellular enzymes. M cultures produce 10 to 15 times more extracellular protease than do wild-type cultures. This protease derives from $M$ cells and not from segregants since (i) there is a linear correlation between the proportion of $M$ cells in the cultures and the protease activities in the supernatants, (ii) protease production stops or slows down before the segregants accumulate and (iii) most isolated B segregants do not overproduce protease and TD segregants are too rare to account for this activity. The kinetics of protease production is similar in M, wild-type and ScoC strains. In M cultures most protease is made during the 'critical period'.

As with various stable Sco mutants (Dod et al., 1978), overproduction of protease is related to delay in spore formation. The longer the 'critical period', the longer the period over which the enzyme is produced and the higher the final protease activity.

Although most B segregants are wild-type-like with respect to both the levels and the kinetics of protease production, B(D) strains produce much higher amounts but with normal kinetics. Their behaviour resembles that of stable ScoC mutants (Dod et al., 1978), confirming the presence of a $S c o C$-type mutation in M strains and their segregants (Zucca \& Balassa, 1979).

The interpretation of the results with TD strains is more complex. Protease production is about twice that of $M$ strains. The same arguments as given above for $M$ cultures suggest that most of the activity is produced by TD cells. M cells could, however, contribute some of the protease activity. The enzyme is produced at a constant rate for a long time.

TDst strains sporulate at low frequency and most cells remain blocked at stage 0 . They produce the highest protease activities (up to 60 times the wild-type level), in fact, greater than those of two industrial strains (J. Zucca \& G. Balassa, unpublished). Protease is produced continuously from $t_{0}$ to about $t_{10}$, at a constant rate.

In general, the protease-overproducing strains indicate a relationship between the overproduction of protease and delayed sporulation, namely the accumulation of cells at stages III and V. In this respect too, the results resemble those obtained with various stable Sco mutants, so that the kinetics of sporulation and of protease production can be considered in the same way (Dod et al., 1978). All the results are consistent with the hypothesis that the genetic anomaly of $\mathrm{M}$ and TD strains affects the normal time course of the sequential activation and de-activation of sporulation genes. In $M$ and $B(D)$ strains the rate of enzyme production is mainly affected while in TD and TDst strains not only is this rate high but enzyme production does not stop until very late. Assays in the presence of the specific inhibitor PMSF showed that in strains which differed in proteolytic activity up to 60-fold, the proportions of the two proteases (the sporulation-associated alkaline protease and the neutral protease) remain the same. Thus, synthesis of the two enzymes is coordinated and subjected to common quantitative regulation, as found with stable Sco mutants (Dod et al., 1978; Dod \& Balassa, 1978). Commitment to sporulation is, however, a prerequisite for the production of alkaline but not of the neutral protease. Therefore, in strains where this commitment is apparently delayed (FS437), only neutral protease is produced at first.

$\alpha$-Amylase production is known to be independent of sporulation. The enzyme is synthesized at normal (or slightly elevated) levels by most Sco mutants (Dod et al., 1978) as well as 
by the $\mathrm{M}$ and TD strains. Apparently, there is no coordination between the regulation of protease and $\alpha$-amylase production. Surprisingly, the $\mathrm{B}(\mathrm{D})$ strain and the TDst strains extensively overproduce $\alpha$-amylase, but, even so, there is no quantitative correlation between the levels of the two enzymes. These observations, although unexplained, show the complexity of the regulation of the extracellular enzymes produced during sporulation. The view that some of these enzymes are entirely under sporulation control while others remain completely independent of the sporulation process is oversimplified and should be abandoned (see also discussion in Balassa et al., 1978; Dod \& Balassa, 1978).

We thank Miss Irène Barros for excellent technical assistance. This work was supported by a grant from the Scientific Affairs Division of NATO, Brussels. J. C. F. Sousa was a fellow of the Gulbenkian Foundation, Lisbon, Portugal.

\section{REFERENCES}

Aubert, J. P., Ryter, A. \& Schaeffer, P. (1968). Comportement de l'ADN des bactéries et des spores au cours d'un cycle sporal chez B. subtilis. Annales de l'Institut Pasteur 115, 989-1007.

Aubert, J. P., Ryter, A. \& Schaeffer, P. (1969). Fate of spore deoxyribonucleic acid in sporulating Bacillus megaterium. In Spores $I V$, pp. 148-158. Edited by L. L. Campbell. Bethesda, Md: American Society for Microbiology.

BALASSA, G. (1969). Biochemical genetics of bacterial sporulation. I. Unidirectional pleiotropic interactions among genes controlling sporulation in Bacillus subtilis. Molecular and General Genetics 104, 73-103.

Balassa, G., Dod, B. \& ZuCCA, J. (1978). Overproduction of sporulation-associated extracellular protease in Bacillus subtilis mutants. In Spores VI, pp. 279-281. Edited by Ph. Gerhardt, R. N. Costilow \& H. L. Sadoff. Washington, D.C.: American Society for Microbiology.

DoD, B. \& Balassa, G. (1978). Spore control (Sco) mutations in Bacillus subtilis. III. Regulation of extracellular protease synthesis in the spore control mutations ScoC. Molecular and General Genetics 163, 57-63.

Dod, B., Balassa, G., Raulet, E. \& Jeannoda, V. (1978). Spore control (Sco) mutations in Bacillus subtilis. II. Sporulation and the production of extracellular proteases and amylase by Sco mutants. Molecular and General Genetics 163, 45-56.

DoI, R. H. (1972). Role of proteases in sporulation. Current Topics in Cellular Regulation 6, 1-20.

Milhaud, P., Balassa, G. \& Zucca, J. (1978). Spore control (Sco) mutations in Bacillus subtilis. I. Selection and genetic mapping of Sco mutants. Molecular and General Genetics 163, 35-44.

Millet, J. (1970). Characterization of proteinases excreted by $B$. subtilis Marburg strain during sporulation. Journal of Applied Bacteriology 33, 207-219.

Ryter, A. \& Aubert, J. P. (1969). Étude autoradiographique de la synthèse de l'ADN au cours de la sporulation de Bacillus subtilis. Annales de l'Institut Pasteur 117, 601-611.

SCHAEFFER, P. (1969). Sporulation and the production of antibiotics, exoenzymes and exotoxins. Bacteriological Reviews 33, 48-71.

Sousa, J. C. F., Silva, M. T. \& Balassa, G. (1978). Spore control (Sco) mutations in Bacillus subtilis. V. Electron microscope study of delayed morphogenesis. Molecular and General Genetics 163, 285291.

ZuCCA, J. \& Balassa, G. (1979). Genetic instability of sporulation-associated characters in a Bacillus subtilis mutant: analysis of the segregation pattern and genetic studies. Journal of General Microbiology 112, 269-281. 